\title{
Parkinsonism Mimicking Rheumatoid Arthritis
}

PRASANTA PADHAN, MD; DEBASHISH DANDA, MD, DM, Department of Clinical Immunology and Rheumatology, Christian Medical College, Vellore, 632004 India. Address correspondence to Dr. P. Padhan; E-mail: prasanta.padhan@gmail.com. J Rheumatol 2010;37:1266; doi:10.3899/jrheum.091473

Originally described in 1864, striatal deformities of the hand and foot are abnormal postures seen in Parkinson's disease even in the early stages and in other parkinsonian disorders ${ }^{1}$. The term striatal is used, as pathology in the neostriatum (putamen and caudate) has been suggested to cause the deformities, but the pathogenesis is unknown. Misdiagnosis of the deformities is common - particularly when they occur early and in the absence of cardinal parkinsonian signs - because the hand deformities are similar to those in rheumatoid arthritis (RA), equinovarus foot deformity typically suggests an orthopedic problem, and toe extension may be thought to be the Babinski sign of upper motor neuron syndromes ${ }^{2}$.

Our patient, a 56-year-old woman, presented with stiff- ness with deformities in both hands of 6 months' duration. Examination of hands revealed "swan-neck" deformity in the left index finger, with flexion at the metacarpophalangeal joints (Figure 1). She also had equinovarus foot deformity (Figure 2). There was no joint swelling or tenderness. She had no radiological or serological features of RA. On neurological examination she was found to have classical features of Parkinson's disease - tremor, bradykinesia, and rigidity.

\section{REFERENCES}

1. Aydog E, Eksioglu E, Cakci A, Yilmaz O. Hand deformity in Parkinson's disease: case report. Rheumatol Int 2005;25:548-9.

2. Ashour R, Tintner R, Jankovic J. Striatal deformities of the hand and foot in Parkinson's disease. Lancet Neurol 2005;4:423-31.

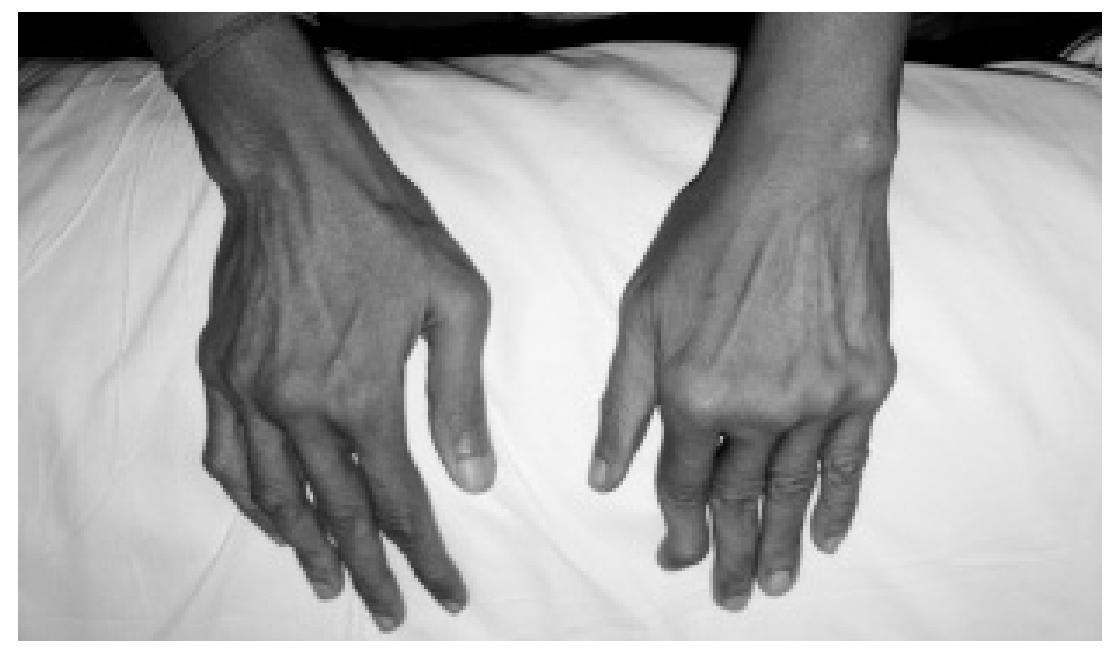

Figure 1. "Swan-neck" deformity in the left index finger, with flexion at the metacarpophalangeal joints.

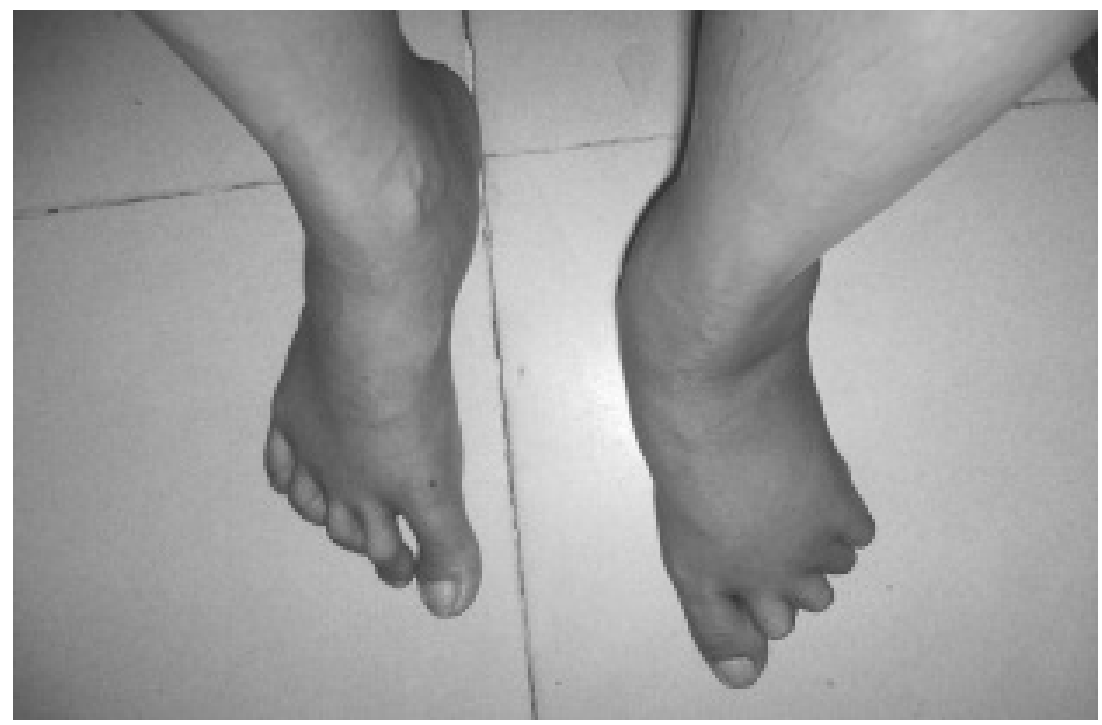

Figure 2. The patient also had equinovarus foot deformity. 